\title{
Construções atributivas em Kwazá
}

\author{
Attributive constructions in Kwaza
}

Hein van der Voort ${ }^{\mathrm{I}}$

Resumo: Este artigo trata de modificação atributiva em Kwazá, uma língua não-classificada de Rondônia, Brasil. Nesta língua, não há adjetivos, pronomes relativos ou outra marca de relativização. Ambos são expressados por justaposição de substantivos em sintagmas nominais, em que um dos constituintes modifica o outro. O substantivo modificador pode ser monomorfêmico ou ter maior complexidade e consistir de morfemas ou constituentes múltiplos, razão pela qual não se faz distinção entre adjetivos e cláusulas relativas em Kwazá. Toda modificação atributiva é realizada por justaposição de substantivos.

Palavras-chave: Morfossintaxe. Sintagmas nominais. Adjetivos. Relativização.

Abstract: This article deals with attributive modification in Kwaza, an unclassified indigenous language of Rondônia, Brazil. In this language there are neither adjectives nor relative pronouns or any other token of relativisation. Both are expressed by juxtaposition of nouns in nominal phrases, where one of the constituents modifies the other. The modifying noun may be monomorphemic or have greater complexity and consist of multiple morphemes or constituents. Therefore, no distinction can be made between adjectives and relative clauses in Kwaza. All attributive modification is realised through juxtaposition of nouns.

Keywords: Morphosyntax. Noun phrases. Adjectives. Relativisation.

I Universidade de Radboud de Nimega. Pesquisador. Amsterdã, Holanda/Países Baixos (hvoort@xs4all.nl).

Museu Paraense Emílio Goeldi. Pesquisador visitante.

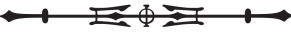




\section{INTRODUÇÃO}

O Kwazá (antigamente conhecido como Koaiá) é uma língua indígena do Brasil, falada por cerca de 25 pessoas no sul do estado de Rondônia, Brasil. A língua está altamente ameaçada de extinção, especialmente porque a transmissão para as novas gerações está em perigo. A filiação genética da língua ainda não foi estabelecida e a possibilidade de que se trate de uma língua isolada não pode ser eliminada. Os únicos trabalhos sobre a língua são do presente autor, entre eles uma descrição abrangente e alguns artigos (VAN DER VOORT, 2002a, 2002b, 2003, 2004).

As classes gramaticais da língua incluem verbos, nomes, advérbios e alguns partículas pragmáticas. Em Kwazá não há uma classe de adjetivos. A ordem das palavras na sentença é bastante livre, dependendo de fatores pragmáticos, mas a ordem SVO (Sujeito-Verbo-Objeto) ocorre mais freqüentemente. O Kwazá é uma língua morfologicamente bastante complexa e a maioria das formas presas são sufixos verbais. Além de cláusulas matrizes, de valor declarativo, imperativo, interrogativo etc., distingue-se morfologicamente cláusulas co-subordinadas verbais ${ }^{1}$; cláusulas subordinadas adverbiais de valor condicional, temporal etc.; e cláusulas nominais que funcionam como complemento de verbos ou como modificador de nomes. As distinções entre estes tipos de cláusulas são marcadas por sufixos no final do verbo. A morfologia flexional de substantivos é relativamente simples; existe somente marcação de caso de objetos animados e alguns marcadores de funções semânticas de argumentos satélites. Não existe marcação flexional de número ou gênero.

No Kwazá, a ordem dos morfemas dentro da palavra é relativamente fixa. A palavra geralmente consiste de uma raiz e alguns sufixos. Os primeiros sufixos que seguem a raiz são caracterizáveis como derivacionais. São morfemas que mudam o sentido da palavra, criando uma nova, como classificadores, sufixos de direção, tempo e aspecto, valência e outros. Os sufixos derivacionais são seguidos pelos sufixos com valores mais flexionais. Estes sufixos mudam a forma da palavra, como sufixos de caso, pessoa de sujeito, e de modo. $O$ exemplo (1) mostra algumas destas características básicas de formação das palavras em Kwazá:

\begin{tabular}{|c|c|c|c|c|c|}
\hline \multicolumn{2}{|l|}{ atxitxi 'mũ } & \multicolumn{4}{|c|}{ kui'nãxare } \\
\hline atxitxi & $-m \tilde{u}$ & kui & -nã & $-x a$ & -re \\
\hline milho & -CL:líquido & beber & -FUT & -2 & -INT \\
\hline Substantivc & o-Classificador & Verbo & -Tempo & -Pessoa & -Modo \\
\hline & -DERIVAÇÃO & RAZZ & -DERIVAÇÃO & -FLEXÃO & -FLEXÃO \\
\hline
\end{tabular}

Nota-se que Kwazá é uma língua pro-drop, onde a flexão de pessoa do sujeito tem valor pronominal. $\bigcirc$ uso de um pronome explícito neste exemplo estaria supérfluo e indicaria ênfase contrastiva pragmática.

Cláusulas co-subordinadas têm como núcleo um verbo marcado pelo elemento modal -ta / -tja 'Cso'. Gramaticalmente são cláusulas subordinadas à cláusula matriz, mas do ponto de vista semântico são coordenadas e têm o mesmo valor modal. Textos narrativos consistem geralmente de cadeias compridas de cláusulas co-subordinadas, que são terminadas por uma cláusula matriz de valor modal declarativo, interrogativo etc. Estas construções são conhecidas na literatura (FOLEY; VAN VALIN, 1984) como cláusulas cosubordinadas ou cláusulas mediais.

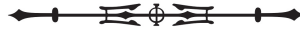


O acento principal da palavra em isolamento cai na última silaba da raiz ou da raiz estendida. A raiz (estendida), na definição usada aqui, inclui morfemas derivacionais, mas não as flexões. Observa-se que a flexão do sujeito de $3^{\text {a }}$ pessoa é zero e que a indicação morfológica de objetos em verbos transitivos não é considerada como flexão in stricto sensu.

Embora no Kwazá a morfologia nominal seja relativamente simples em comparação com a morfologia verbal, a operação de nominalização permite substantivos de grande complexidade interna. Neste artigo será discutido como se exprimem noções atributivas em Kwazá e qual é o equivalente do que em outras línguas é conhecido como relativização.

\section{MODIFICAÇÃO ATRIBUTIVA}

A ausência no Kwazá de uma categoria gramatical de adjetivos não proíbe a expressão de noções atributivas. Em lugar de adjetivos são usados substantivos na função de modificadores atributivos. Toda modificação atributiva de substantivos realiza-se por meio de justaposição do substantivo modificador, o dependente, com o substantivo principal, o núcleo da construção. O dependente pode ser um substantivo monomorfêmico, ou um substantivo derivado de um verbo ou advérbio. Pelos exemplos (2) a (5) será demonstrada a construção atributiva mais básica: a justaposição de substantivos simples.

(2) $y w y^{\prime} n w \tilde{y}$ duma'ru

árvore concha

'concha de madeira'

\section{(3) koreja'ri amũ'tay}

prato vidro

'prato de vidro'

$\begin{array}{lc}\text { da'mũ } & \text { tswa } \\ \text { pato } & \text { homem } \\ \text { 'pato masculino' }\end{array}$

(5)

$\begin{array}{lcc}\text { hiri 'ni } & \text { zjwau } & \text { isi 'xwe-ki } \\ \text { pajé } & \text { João } & \text { tratar-DEC } \\ \text { 'Pajé João está tratando (alguém).' }\end{array}$

Muitos substantivos são baseados em raízes verbais e contêm morfemas nominalizadores e classificadores. A raiz verbal do modificador nos exemplos (6) e (7) tem um valor semântico atributivo, 'ser grande':

(6) $k \varepsilon w \varepsilon^{\prime} p \varepsilon \quad t x i-{ }^{\prime} h \tilde{y}-t \varepsilon$

barata grande-NOM-NOM

'barata grande'2

2 O nominalizador - $t \varepsilon$ tem uma conotação resultativa ou intensificadora. A raiz txi- 'estar grande' pertence à uma classe de raízes verbais que normalmente vêm seguidas por um classificador específico ou o nominalizador - hỹ , antes de qualquer outra derivação ou flexão. Este grupo inclui também raízes numerais e outros verbos encontrados neste artigo, como aky- 'estar dois', axe- 'achar', nỹ- 'estar grande'. 
(7) tsitõ'jẽ txi-tõi-'te

estrela grande-CL:redondo-NOM

'estrela grande'

O componente modificador pode ser um argumento da raiz verbal de uma nominalização. No exemplo (8), a palavra wade'xyi 'palha' pode ser considerada argumento do verbo bu- 'botar':

(8)
wade'xyi
bu-ni'te
tucum-CL:cabelo
chapeu-INS
'chapéu de palha' (lit. 'coisa de palha de botar (na cabeça)')

Sintagmas nominais atributivos podem consistir de vários substantivos justapostos:

(9)
tã'jã
wade-'xyi
bu-ni'te
wai' $h \tilde{y}-h \tilde{y}$
'e-ki
cacique
tucum-CL:cabelo
chapeu-INS bonito-NOM
ter-DEC
'O cacique tem um chapéu bonito feito de tucum.'

Neste exemplo, o objeto do predicado é um sintagma nominal que consiste do núcleo buni'te 'botar', que é modificado por wade'xyi 'fibras de tucum' e wai'hỹhỹ 'coisa bonita'. O número máximo de substantivos justapostos parece ser limitado. No exemplo (10), não havia mais possibilidade de adicionar o substantivo wai'hỹhỹ 'coisa bonita':
axe'hỹ-da-ki
tã'jã
wade- 'xyi
bu-ni'te 'bu-hỹ
achar-1S-DEC
cacique
tucum-CL:cabelo
chapeu-INS botar-NOM
'Encontrei o cacique com chapeu de palha de tucum na cabeça.'

Geralmente, a ordem dos constituintes de construções atributivas é núcleo-dependente, mas a ordem dependente-núcleo também é encontrada, como em (2) e (8).

\section{Modificador atributivo sem modificado explícito}

Sob circunstâncias determinadas, pode-se omitir o núcleo de uma construção atributiva. Sozinha, a palavra txitõi'tc, do exemplo (7), significa 'coisa de forma redonda grande', que é o sentido literal. Sem um núcleo explícito, depende do contexto pragmático de uso se a interpretação é 'olho', 'estrela' etc. Da mesma maneira pode-se omitir os núcleos encaixados nas construção atributiva dispostas no exemplo (11):

$$
\begin{array}{lll}
((h i r i ' n i) & \text { jere'xwa) } & \text { a're-wa-hỹ } \\
\text { pajé } & \text { onça } & \text { virar-IS-NOM }
\end{array}
$$

No contexto das lendas tradicionais dos Kwazá, entende-se que jere' $x$ wa a'rewahỹ significa um pajé que virou onça e, se já foi mencionado uma vez na mesma história, a' rewahỹ sozinho já serve para esta interpretação.

\section{Construções possessivas}

Em Kwazá, não existem pronomes possessivos ou flexões possessivas. A expressão de uma relação possessiva involve a derivação do substantivo possuidor pelo morfema possessivo - $d y$-, seguido por um morfema nominalizador. Descontando a estrutura interna morfológica do substantivo dependente, não há diferença 
entre construções possessivas e atributivas. Construções possessivas apresentam as mesmas características que as construções atributivas. O primeiro substantivo está em justaposição com o segundo que ele modifica, como pode ser visto nos exemplos (12) e (13).

$\begin{array}{ll}\text { 'si-dy-hỹ } & a^{\prime} x y \\ \text { eu-POS-NOM } & \text { casa } \\ \text { 'minha casa' } & \end{array}$

$$
\begin{array}{ll}
\text { haru'rai-dy-hỹ } & \text { lo'te } \\
\text { tatu-POS-NOM } & \text { entrada } \\
\text { 'entrada (ao buraco) do tatu' }
\end{array}
$$

Se o contexto pragmático permite o núcleo pode ser omitido. Sozinho, a palavra 'sidyhỹ, exemplo (12), significa literalmente 'o meu', mas no contexto apropriado pode significar 'a minha casa'. E no exemplo (14), o núcleo eto'hoi 'filho' está entendido só no contexto apropriado.

$$
\begin{array}{ll}
\text { na-'ay- } h \tilde{y}-d y-h \tilde{y} & \text { i'si-ki } \\
\text { PROX-isso-NOM-POS-NOM morrer-DEC } & \text { '(O filho) daquela pessoa morreu.' }
\end{array}
$$

A ordem dos constituintes de construções possessivas é normalmente dependente-núcleo, mas também se encontra a ordem núcleo-dependente, como no exemplo (15).

$$
\begin{array}{ll}
a^{\prime} x y & ' s i-d y-x y \\
\text { casa } & \text { eu-POS-CL:casa }
\end{array}
$$

'minha casa'

\section{O papel do classificador}

Em Kwazá, existe um grande número de morfemas presos com uma carga semântica bem concreta e específica, que funcionam como classificadores. Eles têm uma distribuição grande e podem ocorrer em substantivos e verbos. Estes morfemas indicam a filiação de substantivos em certas classes e também podem identificar constituintes de sintagmas verbais e nominais por meio de congruência. Além disso, o classificador pode substituir o nominalizador -hỹ e assim funcionar como nominalizador com um conteúdo semântico específico. De fato, considera-se o nominalizador -hỹ como classificador neutro, de valor semântico genérico, recomendando-se a comparação entres os exemplos (12) e (15).

Neste caso é possível omitir o núcleo do sintagma em qualquer contexto pragmático, sem tornar ambíguo: sozinho, 'sidyxy significa 'a minha casa' em qualquer situação. Compare-se também os exemplos (16) e (17).
(16) tawi'wi-dy-hỹ
Tavivi-POS-NOM
'casa de Tavivi'

\section{$a^{\prime} x y$}
casa
(17) tawi'wi-dy-xy
Tavivi-POS-CL:casa
'casa de Tavivi'

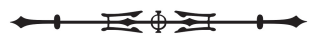


Faltando uma classe de adjetivos, muitos conceitos que se expressam com adjetivos em outras línguas ocorrem em Kwazá como verbos, por exemplo, a noção 'frio' é representada no Kwazá como awy- 'estar frio'. Nota-se que estas raízes verbais semanticamente atributivas são raízes presas e sempre precisam ser seguidas por flexões verbais ou por um nominalizador ou um classificador. Os exemplos (18) e (19) mostram, então, que classificadores permitem, também na construção atributiva (e não somente na construção possessiva), a omissão do núcleo em qualquer contexto pragmático, sem perda de compreensibilidade.

$$
\begin{aligned}
& \text { awy-' } h \tilde{y} \\
& \text { frio-NOM } \\
& \text { 'a (coisa) fria' } \\
& \text { awy-'mũ } \\
& \text { frio-CL:líquido } \\
& \text { 'água fria' }
\end{aligned}
$$

No exemplo (18), o classificador depende completamente do contexto do qual é o referente do enunciado nominal, mas no (19) está claro que se trata de líquido, normalmente interpretado como água. É evidente que, se não especificado por um núcleo explícito como hã 'água', depende, ainda, do contexto pragmático se o referente em (19) é um rio, somente água, café ou leite etc.

Um grupo pequeno de raízes verbais de valor semântico atributivo exige a aplicação do morfema atributivo $-\tilde{y}$-. Não obstante em todo o resto esse grupo comporte-se da mesma maneira que as outras raízes presas em sintagmas nominais. Observem-se os exemplos (20) e (21):

$$
\begin{aligned}
& \text { ho' } h o-\tilde{y}-h \tilde{y} \\
& \text { preto-ATT-NOM } \\
& \text { 'a (coisa) preta' }
\end{aligned}
$$

$$
\begin{aligned}
& \text { ho'ho- } \tilde{y} \text {-siki } \\
& \text { preto-ATT-CL:pele } \\
& \text { 'roupas pretas' }
\end{aligned}
$$

Nota-se que o morfema atributivo também pode ser aplicado em outras raízes, como raízes adverbiais e nominais/ nominalizadas. Depois de nominalização por classificador, estes substantivos complexos também podem funcionar como modificador, com ou sem núcleo, como pode ser visto nos exemplos (22), (23) e (24).

$$
\begin{array}{lll}
\tilde{a}^{\prime} w \tilde{y} i-d a-k i & a^{\prime} x y & \text { tjaỹa'tje- } \tilde{y}-x y \\
\text { ver-1s-DEC } & \text { casa } & \text { perto-ATT-CL:Casa }
\end{array}
$$

'Eu vi a casa próxima.'

$$
\begin{array}{ll}
\text { xyi-dy-'rjỹ-ỹ-hỹ } & \text { koreja'ro } \\
\text { você-POS-CL:área-ATT-NOM } & \text { panela } \\
\text { 'a panela do seu lugar' } &
\end{array}
$$

\section{panela}

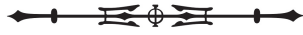




\author{
aka'rwe- $\tilde{y}-n w \tilde{y}$ \\ para.lá-ATT-CL:árvore \\ 'o árvore mais para lá'
}

Em Kwazá, também as noções numerais e demonstrativas são expressas por raízes verbais presas nominalizadas. Da mesma maneira, os classificadores permitem a omissão do núcleo em sintagmas nominais, sem tornar ambíguo, como disposto em (25) e (26).

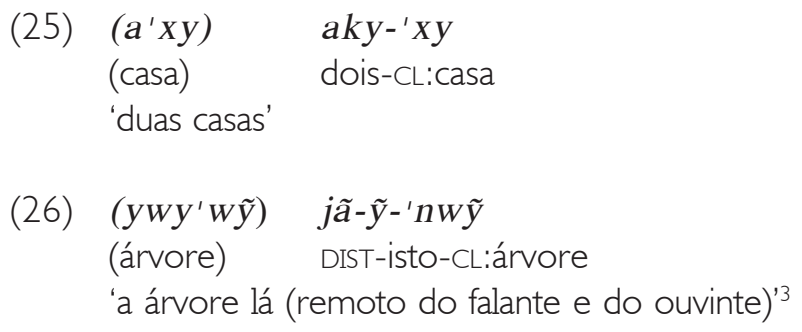

\title{
CLÁUSULAS ATRIBUTTVAS
}

Como mencionado na introdução, a distinção entre cláusulas matrizes e cláusulas verbais (co-)subordinadas é marcada morfologicamente por sufixos de modo. Além disso, o nominalizador -nãi marca cláusulas nominais para funcionar como adverbiais ou complementos de verbos de cognição. Não havendo em Kwazá pronomes relativos ou outras maneiras específicas para marcar relativização ou cláusulas relativas, é o morfema nominalizador geral e classificador neutro -hỹ que serve para este fim. O morfema -hỹ nominaliza sintagmas verbais de qualquer grau de complexidade e o resultado é um substantivo que pode ser usado como cláusula atributiva. Comparem-se os exemplos (27) e (28):
(27) haru'rai i'si-tse tatu morrer-DEC
'O tatu morreu.'

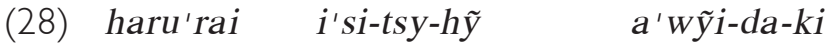
tatu morrer-GER-NOM ver-1 S-DEC
'Eu vi o tatu morto.'4

O enunciado do (27) foi nominalizado no exemplo (28). Neste caso, o sintagma nominalizado funciona como objeto do verbo matriz, a'wỹidaki 'eu vi', e consiste de um núcleo, haru'rai 'tatu', e um substantivo

\footnotetext{
3 Nota-se que em (26) o elemento ỹ- 'isto', é uma das raízes demonstrativas, e a homofonia com o morfema derivacional -ỹ- 'ATT' é coincidência. Nota-se também que, em combinação com o prefixo distal jã- 'DIST', o elemento ỹ- 'isto' já não tem mais a conotação de proximidade.

${ }^{4}$ A função do morfema gerundivo -tsy-, que é homófono com o morfema potencial, não está completamente entendida. Neste exemplo, -tsy- pode ter algum tipo de valor enfático.
} 
dependente e modificador do núcleo, i'sitsyhỹ 'o morrido'. Propõe-se chamar o modificador nominalizado de cláusula atributiva e de considerá-las junto com o núcleo como constituintes da construção atributiva, em analogia com a definição de construções relativas em Lehmann (1984). Nesta definição, o núcleo representa o núcleo da construção atributiva e a cláusula atributiva representa o dependente do núcleo. Ambos, o núcleo e a cláusula atributiva são substantivos e, em justaposição, formam a construção atributiva. A ordem dos constituintes é normalmente núcleo-dependente, mas a ordem inversa foi atestada às vezes.

Nota-se que, como qualquer substantivo em Kwazá, a construção atributiva pode ser verbalizada. No caso de construções atributivas complexas isto pode envolver derivação recursiva, quando a raiz do dependente já consiste de um verbo nominalizado. O resultado parece uma construção clivada, ou seja, o equivalente da construção enfática criada em outras línguas por inserção do verbo 'ser', observado nos exemplos (29) e (30).

(29) jo-ka'c mandioca-CL:barra 'São pedaços de mandioca que eu fritei.'

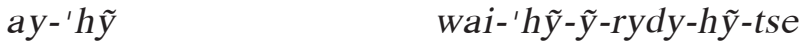

$$
\begin{aligned}
& \text { aquela-NOM bom-NOM-ATT-IRR-NOM-DEC } \\
& \text { 'Seria bom.' (lit. 'É uma coisa que estaria boa.') }
\end{aligned}
$$

\section{Funções sintáticas do núcleo}

Em Kwazá, verbos nominalizados podem ser finitos, no sentido que contêm flexões pessoais, além de derivações indicando categorias gramaticais como tempo e aspecto. Estes verbos nominalizados podem ser justapostos como modificadores atributivos a outros substantivos, que podem funcionar como argumentos latentes da raiz verbal do modificador. Na definição acima, então, o núcleo de uma construção atributiva pode funcionar como argumento do verbo encaixado na cláusula atributiva. Em Kwazá, somente dois tipos de argumentos são, na terminologia de Keenan e Comrie (1977), 'accessíveis' a esta operação: o sujeito e o objeto. No exemplo (31), o núcleo da construção atributiva representa o sujeito do verbo nominalizado intransitivo:

$\begin{array}{llll}\text { (31) la'to } & \text { dutu're } & \text { tsutsu-'hỹ } & \tilde{a}^{\prime} w \tilde{y} i-d a-k i \\ \text { ontem } & \text { porco } & \text { urinar-NOM } & \text { ver-1s-DEC }\end{array}$

'Ontem eu vi um porco urinando.'

O sujeito do verbo encaixado tsutsu- 'urinar', dutu're 'porco', representa o núcleo da construção atributiva dutu're tsutsu' hỹ 'porco que está urinando'. O verbo encaixado é um verbo intransitivo. Para uma construção transitiva, comparem-se os exemplos (32) e (33):

\footnotetext{
5 Nota-se que na $3^{a}$ pessoa pode ocorrer uma forma alternativa do morfema declarativo: -tse ao invés de -ki. Esta forma alternativa ainda não está completamente entendida.
}

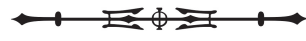




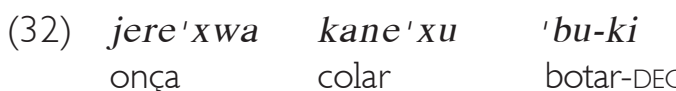

'O cachorro está com colar.'6

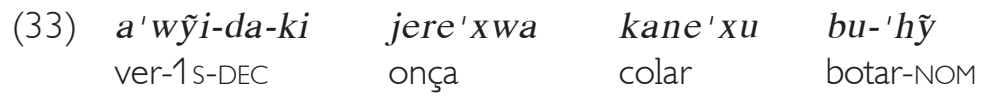

'Vi o cachorro com colar.'

O verbo no exemplo (32), bu- 'botar', é transitivo. No exemplo (33) o enunciado inteiro está nominalizado e ocorre como objeto do verbo matriz a'wỹi- 'ver'. O sujeito de (32), jere'xwa 'cachorro' (lit. 'onça'), representa o núcleo da construção atributiva no exemplo (33). Além disso,jere'xwa representa, ainda, o sujeito da raiz verbal da cláusula atributiva kane'xu bu'hỹ 'alguém que botou colar', em (33). O exemplo (34) mostra mais uma construção atributiva onde o sujeito encaixado é 'relativizado', ou seja, é núcleo:

\section{(34) dutu're ũ'kai-ty-hata-'hỹ a'wỹi-da-hỹ-ki \\ porco deitar-DET-3s.2O-NOM ver-1S-NOM-DEC \\ 'Eu vi aquele porco que deitou na sua (rede).'}

Abre-se aqui um pequeno espaço para maiores esclarecimentos sobre o nominalizador -hỹ. Este tem uma distribuição muito grande, com várias funções. Pode ocorrer como classificador geral, pode ser incorporado no verbo e pode ter efeitos temporais e aspectuais. $O$ verbo matriz deste exemplo parece clivado pelo nominalizador -hỹ e pode ter uma conotação de tempo passado, ou uma conotação enfática, como disposto no exemplo (29). Para uma descrição detalhada das outras funções de -hỹ, recomenda-se ver van der Voort (2004). Nota-se que a ordem das palavras é muito livre em Kwazá e que a posição alternativa do verbo matriz no exemplo (33) é independente da ocorrência ou das conotações possíveis do nominalizador.

Nos exemplos (35) e (36), o núcleo da construção atributiva representa o objeto da raiz do verbo nominalizado encaixado na cláusula atributiva.
(35) $k a^{\prime} w \varepsilon$

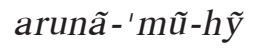
'wai-dy-da-ki
café cozinhar-CL:líquido-NOM bom-CAU-1 S-DEC
'Eu gosto de café novo.'

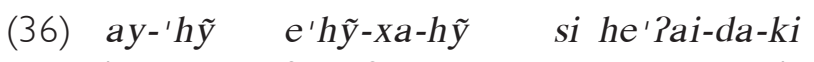
isso-NOM fazer-2-NOM eu não.querer-1s-DEC
'Eu não gosto do que você fez.'

Os exemplos (37) e (38) mostram construções atributivas fora do enunciado matriz, onde é também o objeto que foi relativizado:

\footnotetext{
6 Na falta de termo específico para 'cachorro doméstico', os Kwazá usam o termo jere' $x w a$ 'onça'. A situação é similar na língua dos vizinhos Kanoê, onde o termo envolvido é ope'ra (BACELAR, 2004). Os Aikanã, outros vizinhos tradicionais, têm um termo

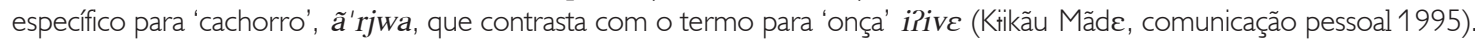


(37) a'ru-xy-nite cruzar-CL:folha-INS

foto

'A foto que eu bati.'7

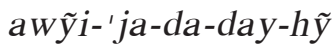

ver-IO-1s-1s-NOM

eu.tendo.visto.alguma.coisa

(38) atxitxi'nũ bare-'ri-da-hỹ

beijú esquentar-CL:plano-1s-NOM

'Beijú que assei.'

\begin{tabular}{|c|c|}
\hline $\begin{array}{l}\text { Sirisi'i } \\
\text { tamanduá }\end{array}$ & $\begin{array}{l}\text { ẽrjãwã-'na } \\
\text { mato-Loc }\end{array}$ \\
\hline
\end{tabular}

'Aquele tamanduá que a onça matou no mato.' (*) $)^{8}$

Além das funções de sujeito e objeto, não foram encontrados núcleos de construções atributivas com outras funções gramaticais com respeito ao verbo encaixado. Ou seja, relativização de outros argumentos ou satélites não foi atestado em Kwazá. Então, em termos da hierarquia de acessibilidade para relativização de Keenan e Comrie (1977), Kwazá ocupa as posições de sujeito e objeto.

Todavia, os exemplos neste artigo não indicam que em Kwazá existe alguma estratégia formal para distinguir sistematicamente entre relativização do sujeito e do objeto. Aparentemente, depende do contexto pragmático se o núcleo de uma construção atributiva representa o sujeito ou o objeto do verbo nominalizado.

\section{Marcação de caso em construções atributivas}

Em Kwazá, a função sintática de sujeito não está expressa por marcação de caso. O objeto recebe o sufixo de caso -w̃a somente se fizer referência a um objeto animado, especialmente humano. Na construção atributiva no exemplo (40), não há nenhuma expressão morfológica de funções sintáticas:

$$
\begin{aligned}
& \text { emũtay-ku'ty-txuhũi eto'hoi ohuini-'hỹ } \\
& \text { vidro-CL:cabeça-pequena criança brincar-NOM } \\
& \text { 'Uma bola de gude pequena para as crianças jogar.' }
\end{aligned}
$$

\begin{tabular}{|c|c|c|}
\hline $\begin{array}{l}\text { etohoi-'wã } \\
\text { crianca-OA }\end{array}$ & $\begin{array}{l}\text { jere' } x \text { wa } \\
\text { onca }\end{array}$ & $\begin{array}{l}k a^{\prime} h \varepsilon-t s y-h \tilde{y} \\
\text { morder-GER-NOM }\end{array}$ \\
\hline
\end{tabular}

Mas no exemplo (41) eto' hoi 'criança' é o objeto do verbo encaixado:

'Eu vi o cachorro que mordeu a criança.'

Neste exemplo, o núcleo da construção atributiva funciona como sujeito na cláusula atributiva. O substantivo encaixado como objeto recebe marcação de caso, que não vem do verbo matriz. No exemplo (42) o

\footnotetext{
7 A dupla ocorrência do elemento -da- '1s' no verbo matriz representa um tipo de reduplicação que cria o sentido de passado remoto (VOORT, 2003).

8 O símbolo (*) após as traduções livres indica que os exemplos não provêm de elicitação de frases isoladas, mas de discurso textual.
} 
objeto da cláusula atributiva é o núcleo da construção atributiva. Esperar-se-ia que houvesse a marcação de caso para objeto animado, mas isto não acontece.

$\begin{array}{lll}\text { jere'xwa } & \text { eto'hoika'he-hỹ } & a^{\prime} w \tilde{y} i-d a-k i \\ \text { onça } & \text { criança morder-NOM } & \text { ver-1s-DEC } \\ \text { 'Eu vi a criança que foi mordida pelo cachorro.' }\end{array}$

Aparentemente, o núcleo de uma construção atributiva não recebe marcação de caso, não obstante represente um objeto humano do verbo encaixado e seja núcleo do objeto do verbo matriz. Nota-se que o morfema gerundivo -tsy- não tem relação com a distinção entre as funções sintáticas dos núcleos em (41) e (42).

Ainda assim, existem ocorrências de marcação de caso em construções atributivas. No exemplo (43), a cláusula atributiva (sem núcleo) si huru'jadahỹwã 'aquele que amei' foi marcada como objeto animado do verbo matriz carißasa- 'matar e jogar fora'.

\begin{tabular}{|c|c|c|c|}
\hline $\begin{array}{l}\text { xyi-'dy-hỹ } \\
\text { você-POS-NOM }\end{array}$ & $\begin{array}{l}a^{\prime} h a \\
\text { pai }\end{array}$ & $\begin{array}{l}\text { si } \\
\text { eu }\end{array}$ & $\begin{array}{l}\text { huru'ja-da-hỹ-wâ } \\
\text { gostar-1 s-NOM-OA }\end{array}$ \\
\hline
\end{tabular}
ca'ri=asa-ty-ta-tay-hỹ-'ki da-ta
matar $=$ deixar-DET-10-10-NOM-DEC 1s-CSO
xyi-dy-'hỹ-wã he?ai-'tja-da-ki
VOCê-POS-NOM-OA não.querer-TRA-1S-DEC
'Porque teu pai matou aquele que amei, não quero teu (pai).' ${ }^{(*)}$

Nos exemplos (44) e (45), cláusulas atributivas são marcadas por causa das suas funções sintáticas com respeito ao verbo matriz, com caso instrumental e locativo, respectivamente:
(44) 'ywynw̃̃
'bukja-hỹ-ko
$' b u=\tilde{u}-r j \tilde{y}-t a$
árvore deitar-NOM-INSTR botar=sentar-CL:área-CSO
'Ele estava sentando numa arvore caída.' (*)

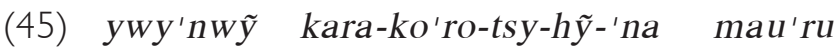 árvore seco-CL:braço-GER-NOM-LOC pica.pau
'O pica-pau mora num ramo duma árvore seca.'
'ũ-ki
sentar-DEC

Estes exemplos sugerem que a marcação de caso oblíquo de sintagmas nominais ocorre no dependente ou no constituinte último.

\footnotetext{
9 A ocorrência livre dos elementos presos da- 'ta '1S-CSO' representa um caso de elipse da raiz verbal e funciona como pronome de ressunção. O fenômeno de elipse morfológica foi discutido em van der Voort (2002a, 2004). Para a reduplicação do morfema -ta'1O' no verbo antecedente, consultar nota 8.
}

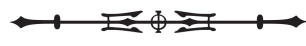




\section{Construções atributivas sem núcleo}

Não existe uma diferença verdadeira entre modificação atributiva e cláusulas 'relativas'. Assim como as construções de modificação atributiva simples discutidas anteriormente, as construções atributivas complexas também podem ocorrer sem núcleo, se o contexto pragmático o permitir. Note-se os exemplos (46) e (47), onde o sujeito encaixado, tswa 'homem', é opcional.

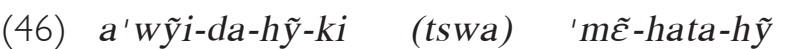

ver-1s-NOM-DEC homem bater-3s.2O-NOM

'Eu vi o (homem) que te bateu.'

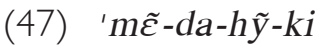

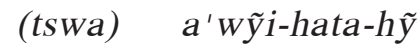

bater-1 S-NOM-DEC homem ver-3s.2O-NOM

'Eu bati o (homem) que te viu.'

No exemplo (48) também falta um núcleo independente, não obstante o verbo encaixado contenha referência explícita ao núcleo pela marcação portmanteau de $3^{\mathrm{a}}$ pessoa sujeito com $2^{\mathrm{a}}$ pessoa objeto:
dutu're hu'hui-ty-hata-hỹ
porco bater-DET-3s.2O-NOM
axe-' hỹ-da-ki
'Encontrei aquele que matou o teu porco.'

Nos exemplos anteriores, os núcleos 'omitidos', ou melhor 'ausentes' ou 'entendidos', funcionam como sujeitos. Nos exemplos (49) e (50), funcionam como objetos:
(49) ay-'hy bo'neka 'ta-wa-hỹ
isso-NOM boneka falar-IS-NOM
'Aquele que chamam de boneca / aquele chamado de boneca.' (*)
(50) tã 'jã ta-wa-'hỹ
cacique falar-IS-NOM
'Aquele que chamam de cacique / aquele chamado de cacique.'

No exemplo (49) o núcleo ay'hỹ 'isso, aquele', funciona como objeto do verbo ta- 'falar'. No exemplo, (50) um núcleo similar com a função de objeto está entendido. Observe-se o exemplo (51), onde o núcleo que funciona como objeto do verbo encaixado kui- 'beber' está ausente:
(51) 'kui-da-hỹ txu'hũi-tse
beber-1s-NOM pequeno-DEC
'Bebi um pouquinho.' (lit. 'O que bebi foi pouco.')

Neste exemplo, pode-se saber somente pelo contexto pragmático qual bebida está entendida. No exemplo (52), o núcleo entendido é lo'te 'porta':
(52) hetsy'se-ko
ce-wa-'hỹ
ku'ro-wa-hy
folha-INSTR
tecer-IS-NOM
fechar-IS-NOM

'(Porta) trançada de folhas para fechar.' 
Essa construção atributiva está sem núcleo, mas contém duas cláusulas atributivas, a primeira delas encaixando um satélite instrumental.

No exemplo (53), o sujeito da raiz verbal da cláusula atributiva e o núcleo que funciona como objeto da mesma raiz estão ausentes.

$$
\begin{array}{ll}
\text { cari=a'sa-(wa)- } h \tilde{y} & \mathrm{e}^{\prime} x y i=\text { exyi-'le- } \tilde{y}-k i \\
\text { matar=deixar-IS-NOM } & \text { cabelo=cabelo-só-ATT-DEC }
\end{array}
$$

'Aquele que mataram teve cabelo muito comprido.'

\section{Classificadores em construções atributivas}

As cláusulas atributivas normalmente terminam no nominalizador -hỹ, que funciona também como classificador geral. Contrário às construções possessivas e modificadoras atributivas mais simples, este nominalizador raramente é substituído por um classificador específico. Ainda assim, existem alguns exemplos de cláusulas atributivas complexas terminando em um classificador específico. Note-se o contraste entre os exemplos (54) e (55):

(54) axy-dy-'xa-tsy-tse

Casa-CAU-2-POT-DEC

'Você vai fazer uma casa.'
(55) a'xy-dy-'xa-tsy-ka'ne a'wỹi-da-ki
Casa-CAU-2-POT-CL:tábua ver-1S-DEC

'Eu vi tábuas para você fazer uma casa.'

Na construção (55), o núcleo está ausente no nivel sintático, mas está presente no nivel morfológico, daí semântico, pelo classificador específico. É possível, mas naturalmente supérfluo, expressar o núcleo explicitamente pelo substantivo independente eka'ne 'tábua' ou com o empréstimo tauba. Em Kwazá, os classificadores podem ter um valor quase pronominal, similar às flexões verbais de sujeito. $\bigcirc$ exemplo (56), uma construção atributiva nominalizada por um classificador, contém um núcleo:

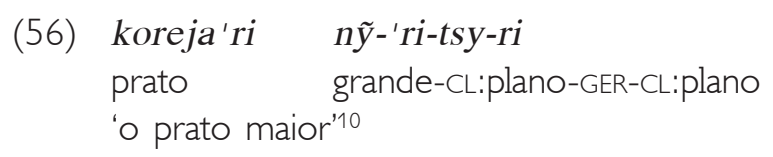

Em princípio o núcleo está supérfluo aqui. Sem núcleo, este enunciado elíptico estaria um pouco mais dependente do contexto pragmático; seria a resposta certa à pergunta 'qual prato é que você quer?'. Seguem os exemplos (57), (58) e (59,) sem núcleo, mas com classificadores específicos:

\footnotetext{
${ }^{10}$ A propriedade mencionada na nota 3, de que raízes verbais como nỹ- 'estar grande' precisam ser seguidos por um nominalizador ou classificador antes de qualquer outra derivação ou flexão, pode levar a múltiplas ocorrências do mesmo nominalizador ou classificador, como neste exemplo.
}

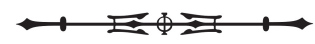


(57) oitsi-'le-tsy-hỹ

e-tsy-ka'ne

copular-RECI-GER-NOM ter-GER-CL:tábua

'fita de video pornográfico'

(58) a'xy ha'je-a-mũ

casa passar-1 p-CL:líquido

'tinta de casa' (lit.: 'O líquido que a gente passa na casa.')

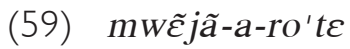

abrir-1 P-CL:porta

'janela' (lit.: 'O buraco que a gente abre.')

\section{Restrição em construções atributivas}

Todas as cláusulas atributivas apresentadas até aqui foram consideradas como restritivas. Como modificadores eles restringem o número de referentes possíveis do núcleo (ou do núcleo entendido). Cláusulas atributivas não-restritivas têm as mesmas características que as restritivas, mas são raras. Parece que somente quando o referente é uma primeira ou segunda pessoa, ou uma terceira pessoa nomeada, a cláusula atributiva é nãorestritiva. Nos exemplos idiomáticos (60) e (61), o núcleo entendido é uma segunda pessoa.

(60) e'tay-xa-re cutsikja-ro'te-xa-hỹ

mulher-2-INT ficar-CL:porta-2-NOM

'Você é uma mulher, que ficas parada na porta?'

(com vergonha de entrar)
(61) ka'tay-xa-re
$k \tilde{u}^{\prime} c \tilde{e}$
paca-2-INT
castanha
ja-xa-'hy
comer-2-NOM
'Você é uma paca, que estás comendo (tantas) castanhas?'

No exemplo (62), o referente é uma terceira pessoa, indicado com nome próprio, então, a cláusula atributiva pode ser somente não-restritiva:

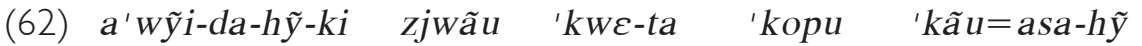
ver-1S-NOM-DEC João entrar-CSO copo quebrar=deixar-NOM
'Eu vi João entrando quebrando copo.'

As possibilidades de expressar a distinção entre interpretação restritiva e não-restritiva de cláusulas atributivas são muito limitadas. Existe, todavia, uma estratégia de exprimir modificação não-restritiva envolvendo cláusulas verbais co-subordinadas. Embora o assunto de co-subordinação seja tratado mais detalhadamente em van der Voort (2004), o contraste entre os exemplos (63) e (64) serve para ilustrar o princípio básico da construção.
(63) ũce'nãi-hỹ
'ja-ki atxi'txi
saber-NOM comer-DEC milho
'(Homens) sabidos comem milho.'

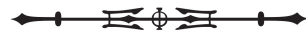


(64) ũce'nãi-hỹ-ta 'ja-ki atxi'txi

saber-NOM-CSO comer-DEC milho

'(Homens,) sendo sabidos, comem milho.'

Enquanto o sujeito de (63) é uma cláusula atributiva sem núcleo, representando aquele sujeito, em (64) o sujeito não está expresso de modo nenhum. O substantivo atributivo de (63) ocorre em (64) como raiz verbalizada de uma cláusula co-subordinada com o verbo matriz.

\section{Imbricação funcional entre cláusulas atributivas e complementos}

O morfema -nãi é um nominalizador de cláusulas complementos. A diferença entre -hỹ e -nãi é que hỹ produz substantivos que representam participantes de eventos e -nãi produz substantivos que representam os eventos mesmos. Substantivos terminando em -nãi são equivalentes aos infinitivos de outras línguas. $O$ exemplo (65) foi dado pelo informante como equivalente exato do (62).

\begin{tabular}{|c|c|c|}
\hline $\begin{array}{l}a^{\prime} w \tilde{y} i-d a-h \tilde{y}-k i \\
\text { ver-1s-NOM-DEC }\end{array}$ & $\begin{array}{l}\text { zjwãu } \\
\text { João }\end{array}$ & $\begin{array}{l}\text { 'kwE-ta } \\
\text { entrar-cso }\end{array}$ \\
\hline
\end{tabular}

'Eu vi que, entrando, João quebrou um copo.'

Aparentemente, o contraste entre (62) e (65) mostra uma possível imbricação funcional entre cláusulas atributivas e cláusulas que funcionam como complemento de certos verbos. A diferença formal entre os dois exemplos provavelmente não consta somente nos nominalizadores diferentes, mas também nos seus diferentes escopos. $\bigcirc$ escopo de -nãi abrange o enunciado inteiro fora de $a^{\prime} w \tilde{y} i d a h \tilde{y} k i$, enquanto na presente análise o escopo de -hỹ abrange somente a última palavra.

\section{CONSTRUÇÕES ATRIBUTTVAS ADVERBIAIS}

Neste artigo falta, ainda, mencionar uma construção adverbial que mostra propriedades similares às da construção atributiva. Em determinadas circunstâncias, descritas em van der Voort (2004), substantivos podem funcionar como advérbios. Além disso, existe um nominalizador com um sentido adverbial temporal, -wy 'tempo de'. Este nominalizador pode ocorrer no lugar do nominalizador canônico -hỹ e pode formar construções adverbiais-nominais bem complexas. Note-se o exemplo adverbial (66):
da'ñ
one $=$ buru-' he-a-xa-wy
$o^{\prime} j \mathrm{j}$-tse
ainda
chegar $=$ passar-NEG-1P-AS-tempo sair-DEC

'Ele saiu antes de nós (exclusivo o ouvinte) chegarmos.' (*)

O resultado da aplicação de -ny pode ser também nominal e funcionar como argumento e modificador de um outro substantivo, coforme pode ser visto no exemplo (67):
$k a^{\prime} w e$
'kui-e-a-tsy-wy
ace'rjy $-k i$
café
beber-de.novo-1P-POT-tempo
fechar-DEC
'O tempo de café está chegando.'

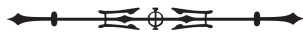


Justaposição de advérbios temporais leva à uma construção nominal modificadora e tais construções podem funcionar como cláusulas adverbiais completamente flexionadas. Observem-se os exemplos (68) e (69):

(68)
txarwa-'wy
o'kja-da-wy
primeiro-tempo
caçar-1s-tempo
'O dia primeiro que eu fui caçar.'

(69)
ay-'wy
tsũ -da-' wy
ui
isso-tempo nadar-1s-tempo
'hu-xa-ki

'No tempo que eu nadei, você fumou.'

\section{CONCLUSÃO}

O padrão geral da construção atributiva em Kwazá é caracterizado por: a) modificação por meio de justaposição de substantivos; b) inexistência de adjetivos; c) inexistência de pronomes relativos ou outros marcadores de relativização; d) inexistência de flexão possessiva; e) expressão destes conceitos por substantivos simples ou, f) por substantivos derivados por nominalizadores. Além disso: g) a língua não distingue formalmente entre modificação por verbos nominalizados dos seus sujeitos e objetos; h) a língua não permite modificação por verbos nominalizados dos seus argumentos oblíquos; i) a ordem dominante dos constituintes de atributivos é núcleo-dependente, enquanto j) a ordem é dependentenúcleo no caso de possessivos; k) o núcleo ausente pode ser representado pelo dependente; e l) não existe uma distinção entre modificação restritiva e não-restritiva. Em vários aspectos a construção atributiva em Kwazá é semelhante a construções atributivas em muitas outras línguas do mundo. Por exemplo, Kwazá tem características a, b, c, e, f, h, i, j, k e l em comum com Groenlandês (Esquimó), mas não d e g (VAN DER VOORT, 1991). Para comparação tipológica com um grande número de outras línguas geneticamente não relacionadas, pode se consultar especialmente Lehmann (1984) sobre construções atributivas e Rijkhoff (2002) sobre sintagmas nominais em geral.

\section{AGRADECIMENTOS}

Agradeço aos Kwaza, Aikanã e Latundê pela hospitalidade infinita. Agradeço especialmente a Mário, ou Kïikãu Mãde, que trabalhou comigo e ensinou-me tanto sobre a sua língua materna. Agradeço à Fundação Nacional do Índio (FUNAI) e ao Conselho Nacional de Desenvolvimento Científico e Tecnológico (CNPq) pelas autorizações que me deram a oportunidade de trabalhar na Área Indígena Tubarão-Latundê. Também à generosa Organização Neerlandesa para Pesquisa Científica (NWO) pelo financiamento do projeto descritivo da língua Kwazá, sob o número 300-72-021. Agradeço a Gale Goodwin Gómez e ao referee anônimo pelos seus comentários e correções.

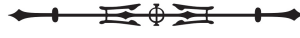




\section{ABREVIATURAS}

\begin{tabular}{|c|c|c|c|}
\hline AS & Pessoa Associada & NOM & Nominalizador \\
\hline ATT & Atributivo & nuc & Núcleo \\
\hline CAU & Causativo & O & Objeto \\
\hline $\mathrm{CL}$ & Classificador & $O A$ & Objeto animado \\
\hline $\mathrm{CSO}$ & Co-subordinação & POS & Possessivo \\
\hline DEC & Declarativo & РОТ & Potential \\
\hline dep & Dependente & PROX & Próximo \\
\hline DET & Detrimental & RECI & Recíproco \\
\hline DIST & Distal & S & Sujeito \\
\hline FUT & Futuro & TRA & Transivizador \\
\hline GER & Gerundivo & V & Verbo \\
\hline INS & Instrumento & 10 & 1a. pessoa objeto \\
\hline INSTR & Instrumental & $1 p$ & 1a. pessoa plural \\
\hline INT & Interrogativo & $1 \mathrm{~s}$ & 1a. pessoa singular \\
\hline IO & Objeto Indefinito & 2 & 2a. pessoa \\
\hline IRR & Irrealis & 3 & 3a. pessoa \\
\hline IS & Sujeito Indefinido & 35.20 & 3a. pessoa sujeito/2a. pessoa \\
\hline LOC & Locativo & & \\
\hline$N$ & Substantivo & - & fronteira de morfemas \\
\hline NEG & Negativo & $=$ & fronteira de composição \\
\hline
\end{tabular}

\section{REFERÊNCIAS}

BACELAR, Laércio Nora. 2004. Gramática da língua Kanoê: descrição gramatical de uma língua isolada e ameaçada de extinção, falada ao sul do estado de Rondônia, Brasil. Tese (Doutorado) - Katholieke Universiteit Nijmegen.

FOLEY, William A.; VAN VALIN, Robert D. 1984. Functional Syntax and Universal Grammar. Cambridge: Cambridge University Press. (Cambridge Studies in Linguistics, 38).

KEENAN, Edward L.; COMRIE, Bernard. 1977. Noun phrase accessibility and universal grammar. Linguistic Inquiry, v. 8, p. 63 99.

LEHMANN, Christian. 1984. Der Relativsatz: Typologie Seiner Strukturen, Theorie seiner Funktionen, Kompendium seiner Grammatik. Tübingen: Gunter Narr Verlag. (Language Universals Series, 3)

RIJKHOFF, Jan. 2002. The Noun Phrase. Oxford: Oxford University Press. (Oxford Studies in Typology and Linguistic Theory).

VOORT, Hein Van Der. 1991. Relative Clauses in West Greenlandic: a descriptive analysis in terms of Functional Grammar. Tese (Mestrado) - Universiteit van Amsterdam.

VOORT, Hein Van Der. 2002a. The quotative construction in Kwaza and its (de-) grammaticalisation. In: CREVELS, Mily et al. (Org.). Current Studies on South American Languages [ILLA/3]. Leiden: Research School of Asian, African, and Amerindian Studies (CNWS). p. $307-328$. VOORT, Hein Van Der. 2002b. Negação em Kwazá (ou koaiá): uma língua viva de Rondônia. In: CABRAL, Ana Suelly Arruda Câmara; RODRIGUES, Aryon Dall'igna (Org.). Línguas Indígenas Brasileiras: fonologia, gramática e história. Atas do I Encontro Internacional do GTL, I. Tomo 2, p. 248-259.

VOORT, Hein Van Der. 2003. Reduplication of person markers in Kwaza. Acta Linguistica Hafniensia, v. 35, p. 65-94.

VOORT, Hein Van Der. 2004. A grammar of Kwaza. Berlin. New York: Mouton de Gruyter. (Mouton Grammar Library, 29).

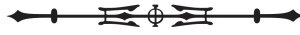




\section{APÊNDICE}

Neste apêndice resumiu-se em uma tabela as estruturas principais encontradas neste artigo. Para cada estrutura foi escolhido somente um ou alguns exemplos. Nota-se que o substantivo $(\mathrm{N}, \mathrm{O}, \mathrm{S})$ e o verbo $(\mathrm{V})$ podem ser internalmente complexos, constituindo-se de raízes verbais nominalizadas, ou incluindo marcadores de pessoa etc. A omissibilidade de constituintes está indicada por parênteses. Constituintes complexos estão indicado por colchetes.

\begin{tabular}{|c|c|c|}
\hline Tipo & Estrutura & Exemplo \\
\hline Modificação atributiva & $\begin{array}{l}N_{\text {dep }}+N_{\text {nuc }} \\
N_{\text {nuc }}+N_{\text {dep }} \\
N_{\text {nuc }}+V-h \tilde{y}-\text { NOM }_{\text {dep }} \\
N_{\text {nuc }}+V-C L-N O M_{\text {dep }} \\
\left(N_{\text {nuc }}+\right) V-h-h \tilde{y}_{\text {dep }} \\
\left(N_{\text {nuc }}+\right) V-C L_{\text {dep }}\end{array}$ & $\begin{array}{r}(2,8) \\
(3,4) \\
(6) \\
(7) \\
(11,18,20) \\
(25,19,21)\end{array}$ \\
\hline Modificação possessiva & $\begin{array}{l}N-P O S-h \tilde{y}_{\text {dep }}+N_{\text {nuc }} \\
N-\text {-POS-CL } L_{\text {dep }}+N_{\text {nuc }} \\
N_{\text {nuc }}+N-\text { POS-CL dep } \\
N-P O S-h \tilde{y}_{\text {dep }} \\
N-P O S-C L_{\text {dep }}\end{array}$ & $\begin{array}{r}(12,13,16) \\
(15) \\
(14) \\
(17)\end{array}$ \\
\hline Construção atributiva & 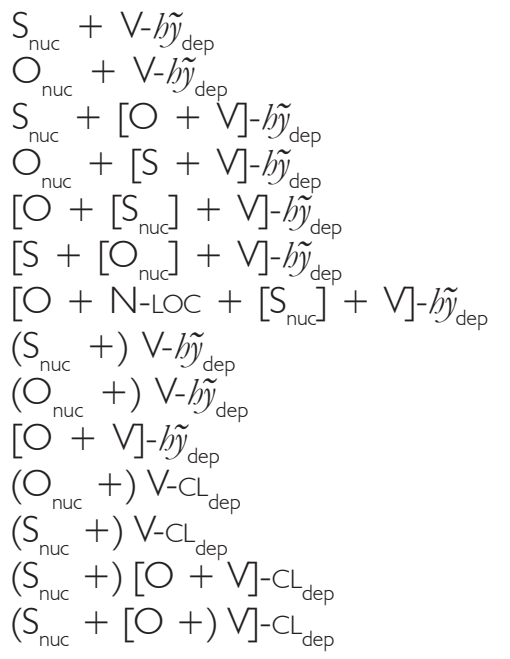 & $\begin{array}{r}(28,34) \\
(35,36,38) \\
(10,33) \\
(40) \\
(41) \\
(42) \\
(39) \\
(46,47,63) \\
(50,51,52) \\
(48) \\
(55) \\
(56) \\
(57) \\
(59)\end{array}$ \\
\hline
\end{tabular}

